\title{
Environmental Toxicants-Induced Immune Responses in the Olfactory Mucosa
}

\author{
Fumiaki Imamura* and Sanae Hasegawa-Ishii \\ Department of Pharmacology, Penn State College of Medicine, Hershey, PA, USA
}

Olfactory sensory neurons (OSNs) are the receptor cells for the sense of smell. Although cell bodies are located in the olfactory mucosa (OM) of the nasal cavity, OSN axons directly project to the olfactory bulb $(\mathrm{OB})$ that is a component of the central nervous system (CNS). Because of this direct and short connection from this peripheral tissue to the CNS, the olfactory system has attracted attention as a port-of-entry for environmental toxicants that may cause neurological dysfunction. Selected viruses can enter the OB via the $\mathrm{OM}$ and directly affect the CNS. On the other hand, environmental toxicants may induce inflammatory responses in the OM, including infiltration of immune cells and production of inflammatory cytokines. In addition, these inflammatory responses cause the loss of OSNs that are then replaced with newly generated OSNs that re-connect

OPEN ACCESS

Edited by:

V. Wee Yong,

University of Calgary, Canada

Reviewed by:

Manu Rangachari,

Laval University, Canada

David Brown

Westmead Institute for

Medical Research, Australia

${ }^{*}$ Correspondence:

Fumiaki Imamura

fimamura@hmc.psu.edu

Specialty section: This article was submitted to

Multiple Sclerosis and

Neuroimmunology,

a section of the journal

Frontiers in Immunology

Received: 22 August 2016

Accepted: 19 October 2016

Published: 04 November 2016

Citation:

Imamura F and Hasegawa-Ishii S

(2016) Environmental

Toxicants-Induced Immune

Responses in the Olfactory Mucosa.

Front. Immunol. 7:475.

doi: 10.3389/fimmu.2016.00475 to the OB after inflammation has subsided. It is now known that immune cells and cytokines in the OM play important roles in both degeneration and regeneration of OSNs. Thus, the olfactory system is a unique neuroimmune interface where interaction between nervous and immune systems in the periphery significantly affects the structure, neuronal circuitry, and immunological status of the CNS. The mechanisms by which immune cells regulate OSN loss and the generation of new OSNs are, however, largely unknown. To help develop a better understanding of the mechanisms involved, we have provided a review of key research that has investigated how the immune response in the OM affects the pathophysiology of OSNs.

Keywords: olfactory epithelium, inflammation, immune system, intranasal administration, olfactory vector hypothesis, olfactory dysfunction, neurodegenerative disease

\section{INTRODUCTION}

We are continuously exposed to a variety of potentially harmful environmental agents, such as bacteria, viruses, mold, dust, pollen, and environmental chemicals. Environmental agents entering the nasal cavity may become allergens, causing inflammation in the olfactory mucosa (OM) (olfactory inflammation), and leading to allergic rhinitis and infectious sinusitis (1). The symptoms are usually associated with hyposmia or anosmia $(2,3)$. Olfactory loss in rhinitis/sinusitis is attributable primarily to blockade of airflow to the olfactory sensory neurons (OSNs) that receive odorous molecules, but damage to the $\mathrm{OM}$ is also considered as a possible cause $(2,4-6)$. In fact, multiple studies have shown that olfactory inflammation causes the loss of OSNs (7-14).

Epidemiological studies have associated exposure to environment toxicants with the incidence of neurodegenerative diseases, including Alzheimer's and Parkinson's diseases $(15,16)$. Since olfactory dysfunction is a common prodromal symptom of these diseases, and because xenobiotics administered into the nasal cavity are often found in the brain, the nasopharynx has attracted 
attention as a port-of-entry for environmental agents that cause neurological disease (the olfactory vector hypothesis) (17-19). To date, a variety of neurotoxicants have been directly administered to the naris of model animals to study their transport to the brain and the resultant neurodegenerative effects in the central nervous system (CNS). Results of these types of studies have now been summarized in a number of reviews (17, 20-22).

Neuroinflammation is a hallmark of neurodegenerative diseases (23-26). Although knowledge of the cause of neuroinflammation is still limited, olfactory inflammation has been proposed as one of the major mechanisms $(27,28)$. Interestingly, allergic rhinitis is associated with development of Parkinson's disease later in life (29). We, therefore, believe that a better understanding of the olfactory immune system will advance our knowledge of the pathogenesis and progression of neurological disease. To date, there are many reports showing that artificially induced olfactory inflammation can cause immune responses and damage to the OM (7-14). Conversely, new OSNs are generated in the OM throughout life, which may help in the repair of damaged tissue $(30,31)$. It also has been reported that immune cells in the OM regulate the depletion of old OSNs and generation of new OSNs. This review summarizes the roles of immune cells in the inflammatory response, tissue damage, and regeneration of the OM with a focus on model systems, primarily the $\mathrm{OM}$ of murine species.

\section{Structure of the Olfactory Mucosa}

The OM is located in the upper region of the nasal cavity, and is made up of the olfactory epithelium (OE) and the underlying lamina propria (Figure 1). The surface of the OE is covered with a mucus layer where inhaled odorant molecules can be trapped, which then bind to odorant receptors expressed on the cilia of the OSNs whose cell bodies are located in the OE. Unlike other receptor cells, OSNs project directly to the olfactory bulb (OB), the first relay station of olfactory information in the CNS, through the cribriform plate. Sustentacular cells line the apical surface of the OE, and provide trophic, metabolic, and mechanical support for OSNs. At the basal surface of the OE, there are two types of basal cells (horizontal and globose basal cells) that give rise to new OSNs and sustentacular cells during lifetime of the organism.

The lamina propria is a layer of connective tissue through which OSN axons pass. OSN axons, although unmyelinated, are gathered into bundles (olfactory nerve) that are wrapped with olfactory ensheathing cells (OECs). OECs are specialized glial cells that are resident in the olfactory system. The lamina propria also contains Bowman's glands and vascular elements. Bowman's glands produce mucus and secrete it to the mucus layer via the OE duct.

\section{Response of Olfactory Mucosa to Intranasal Administration of Environmental Agents}

Inhalation of harmful environmental agents often damages the OM. Here, we focus on the damages associated with inflammatory responses within the nasal cavity (32). Several animal models of human chronic rhinosinusitis have been developed by inoculating bacteria or fungus extract into the mouse nostril $(10,33,34)$. These mouse models have shown inflammatory responses in the nasal cavity, as well as general pathology of the OE that includes mast cell and eosinophilic infiltration into the respiratory epithelium, with increased depth of lamina propria. In addition, olfactory inflammation can be caused by a single compound derived from microbial pathogens, such as polyinosinic:polycytidylic acid [Poly(I:C)] (14), lipopolysaccharide (LPS) (9), satratoxin G (SG), and roridin A (RA) $(7,8,11,13)$. Poly $(\mathrm{I}: \mathrm{C})$ is a synthetic analog of viral double-stranded RNA, and is recognized by Toll-like receptor 3 (TLR3) (35), whereas LPS is an endotoxin found in the outer membrane of Gram-negative bacteria that activates another type of Toll-like receptor, $\operatorname{TLR} 4(36,37)$. When injected intraperitoneally, LPS caused systemic inflammation that also changes the level of inflammatory cytokines in the brain (38). SG and RA are macrocyclic trichothecen mycotoxins produced by fungi such as Stachybotrys chartarum, the "black mold" (39). Immunohistochemical analyses using TLR3 and TLR4 antibodies indicated that sustentacular cells and OECs may be the first target cells of PolyI:C and LPS in the OM, respectively (14, 40). Besides activating different receptors, therefore different types of cells, intranasal inoculation of each of these agents causes an inflammatory response and damage to the OM of rodents. It is useful to review what is known about intranasal inoculation of Poly(I:C), LPS, SG, and RA and their effects on olfactory tissues.

\section{Inflammatory Response}

Infiltration of neutrophils expressing Ly-6G/-6C into the OM occurs 1 day after intranasal inoculation of Poly(I:C), SG, or RA $(7,8,14)$. Kanaya et al. confirmed that Poly(I:C) caused the infiltration of macrophages (F4/80+) and T-lymphocytes (CD3+) (14). In contrast to the situation with neutrophils, which completely disappeared within 6 days, significantly higher numbers of macrophages and T-lymphocytes were observed in the $\mathrm{OM}$ as long as 21 days after the last Poly(I:C) inoculation. In addition, in the OM, Poly(I:C), SG, or RA caused upregulation of mRNAs encoding inflammatory cytokines, including IL-1 $\alpha$, IL-1 $\beta$, IL-6, TNF- $\alpha$, and MIP-2.

\section{Damage of the Olfactory Mucosa}

Intranasal inoculation of environmental agent-derived components also damaged the OM and led to apoptosis of OSNs and decreased thickness of the OE $(7-9,14)$. When Poly(I:C) was inoculated into mouse nostril once a day for 3 days, the number of apoptotic cells was significantly increased and the number of OSNs was decreased in first 3 days. When examined 9 days after the first inoculation (i.e., 6 days after the last inoculation), few apoptotic cells were observed in the $\mathrm{OE}$, but the number of OSNs was less than that observed 3 days post inoculation.

The mechanisms underlying OSN loss associated with olfactory inflammation are currently not well understood. Inflammatory responses seem to play a critical role for death of OSNs. During inflammation, neutrophils and macrophages 


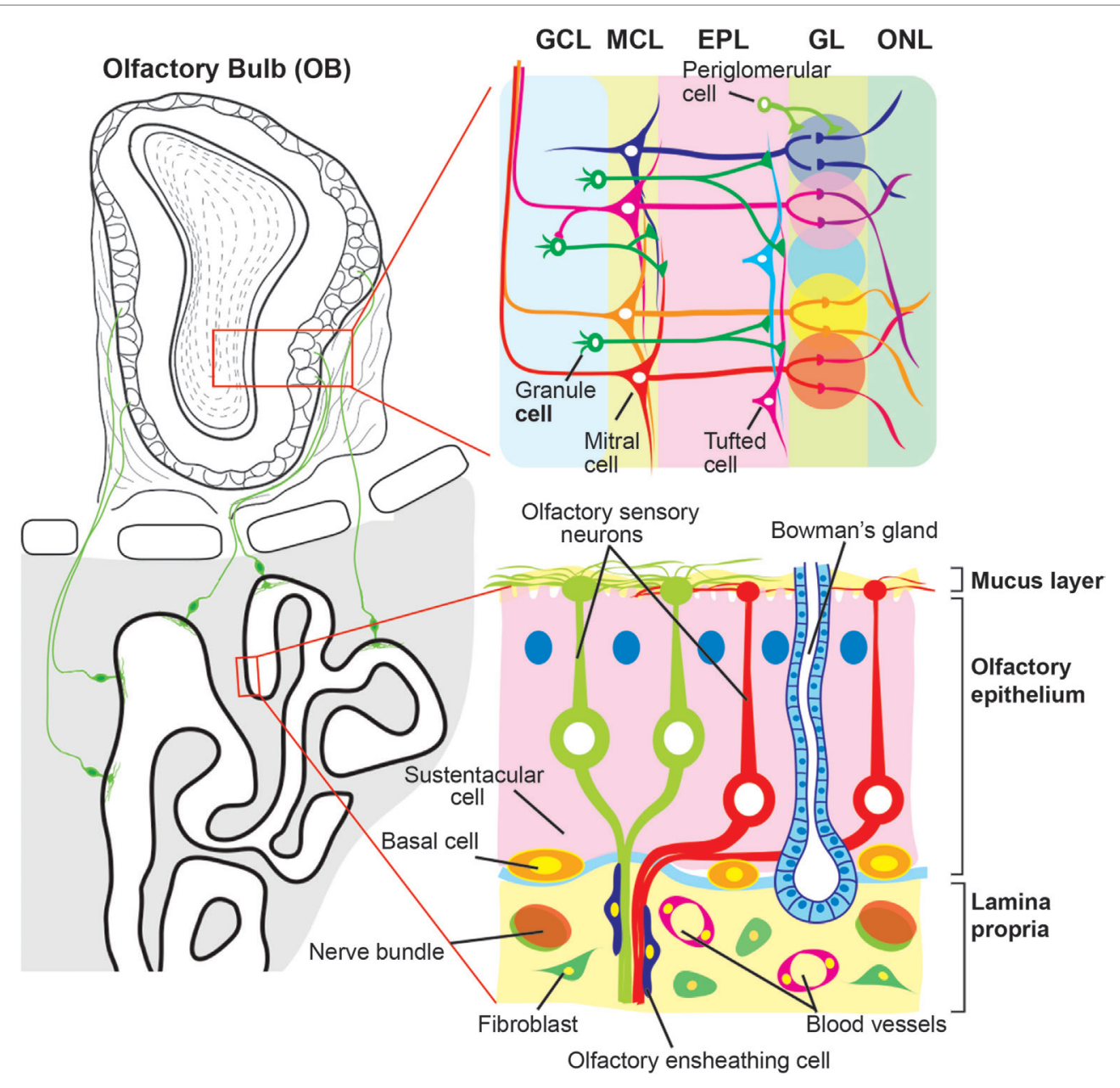

FIGURE 1 | Schematic diagram of the olfactory mucosa and olfactory bulb. The olfactory mucosa is composed of the olfactory epithelium (OE) and the lamina propria. Three types of cells are found in the OE, olfactory sensory neurons (OSNs), sustentacular cells, and basal cells. The dendrites of OSNs project toward the mucus layer where they protrude the cilia expressing odorant receptors. Sustentacular and basal cells are localized at the apical and basal regions of the OE, respectively. The lamina propria is a layer of connective tissue, which lies beneath the OE, and contains fibroblast, blood vessels, and Bowman's gland. OSN axons are fasciculated into bundles that are wrapped with olfactory ensheathing cells and target the olfactory bulb (OB) by passing through the lamina propria and cribriform plate. The OB is divided into multiple layers. Each OSN axon runs the surface of the OB, olfactory nerve layer (ONL), and projects to a glomerulus in the glomerular layer (GL). There, the OSN axons synapse with primary dendrites of projection neurons, mitral and tufted cells, and onto populations of interneurons, periglomerular cells. The secondary dendrites of mitral/tufted cells make dendrodendritic synapses with another population of interneurons, granule cells, in the external plexiform layer (EPL). Beneath the EPL, the OB has the mitral cell layer (MCL) and granule cell layer (GCL) where the cell bodies of mitral cells and granule cells are located, respectively.

secrete elastases, proteases known to break down bacterial membrane proteins (41). Intranasal inoculation of neutrophil elastase caused the loss of OSNs in the OE (14). In contrast, Poly(I:C)-induced damage of the OM was blocked by prior intraperitoneal injection of the neutrophil elastase inhibitor, Silevestat (14). In addition, inflammatory cytokines are also involved in inflammation-induced OSN death. Lane and colleagues created a transgenic, induced olfactory inflammation (IOI) mouse model, in which expression of TNF- $\alpha$ in sustentacular cells was induced with doxycycline as a chronic rhinitis model (12). Using this transgenic mouse, Lane et al. showed that induction of TNF- $\alpha$ expression caused marked reduction of OE thickness and loss of OSNs, whereas the sustentacular cells were unaffected. Concurrent treatment with prednisolone (to inhibit downstream inflammatory responses) prevented OSN loss, therefore suggesting that TNF- $\alpha$ does not directly cause OSN apoptosis (42).

The damage to the OM exacerbates the impact caused by exposure to environmental toxicants. While Staphylococcus aureus is an indigenous microbe found in the nose and usually remains in the lumen after intranasal administration, bacteria can still penetrate the $\mathrm{OE}$ and cause an inflammatory response when inoculated intranasally after first damaging the OM with Triton X-100 or zinc sulfate (43). In addition, tissue damage coupled with an inflammatory response of the OM induced by RA was exacerbated by co-exposure to LPS (8). Although mRNAs encoding inflammatory cytokines were marginally induced by RA alone, co-exposure to both RA and LPS dramatically elevated expression of these genes. 


\section{Regeneration of OE}

Basal cells of the OE give rise to new OSNs and sustentacular cells throughout life $(44,45)$. Damage of basal cells caused by methyl bromide gas, however, led to the eventual loss of OSNs and inhibited the reconstruction of OE (46). In contrast, these basal cells seem to be less affected by intranasal inoculation of Poly(I:C), LPS, or mycotoxins; apoptosis was restricted to OSNs whose cell bodies reside in the middle layer of the $\mathrm{OE}$, below the apical row of supporting cell nuclei and above the basal cell nuclei $(7,8,14)$. Cells expressing Ki67, a proliferating basal cell marker, were increased in number and distributed in all layers of the OE 6 days after the last Poly(I:C) inoculation (14). The OE thickness and the OSN number were almost completely recovered by 21 days post-Poly(I:C) exposure. However, the recovery of OSNs was incomplete (40-50\%), even at 21-28 days after the last inoculation of SG $(7,11)$.

Immune cells and OECs in the $\mathrm{OM}$ also regulate many aspects of degeneration/regeneration of OSNs. The resident macrophages play a key role in the removal of cell debris and stimulation of basal cells to proliferate (47). OEC is known to be a specialized type of glia that wraps OSN axons, as well as serves as a major phagocytic cell type $(48,49)$. Bulbectomy or olfactory nerve transection causes apoptotic death of OSNs by severing the axons and stimulates the generation of new OSNs (50-53). Bulbectomy activates the proliferation of OECs in lamina propria (54) and the infiltration of macrophages into the OM (55). In addition to the phagocyotosis of apoptotic cellular debris, infiltrated macrophages secrete a variety of inflammatory cytokines and chemokines, such as LIF, IL-6, MCP-1, and MIP-1 $\alpha$ (52, 56, 57). It has been proposed that MCP- 1 and MIP- $1 \alpha$ play key roles in recruitment of additional macrophages to the OM and that LIF stimulates globose basal cells expressing LIF receptor (LIFR) (52, $57,58)$. Activation of LIFR subsequently induces iNOS expression that in turn stimulates proliferation of neural precursor cells (59). An increase in iNOS level was also observed in OECs after bacterial challenge to the compromised OM (60).

\section{DISCUSSION}

This review has summarized olfactory inflammation caused by intranasal inoculation of Poly(I:C), LPS, and mycotoxin. Although the receptors and signaling pathways activated by these agents are not identical, they induce similar effects on the OM, including infiltration of immune cells, upregulation of inflammatory cytokines, and loss of OSNs. It appears that damaged and lost OSNs can be replaced with new OSNs since olfactory inflammation has minimal effect on the basal cells. It is not clear, however, whether basal cells are, in fact, affected by olfactory inflammation. The inoculation of toxicants into the IOI-transgenic mouse showed that TNF- $\alpha$-induced inflammation lasted for 6 weeks and compromised the regeneration of OSNs, although the effect was not permanent, suggesting that TNF- $\alpha$ suppresses the proliferative activity of basal cells $(12,61)$. In contrast, intraperitoneal injection of the herbicide 2,6-dichlorobenzonitrile induced inflammation-like pathological changes in OE and depleted the horizontal basal cells, resulting in permanent loss of OSNs (62). A critical next step is to elucidate the molecular mechanisms underlying the specific loss of OSNs and the resistance of basal and sustentacular cells to olfactory inflammation. Since variety of immune cells are involved in inflammatory responses, detailed researches on types of immune cells activated and infiltrated in the OM during olfactory inflammation are required to elucidate the mechanisms.

It is also known that zinc sulfide and hydrogen sulfide administered into the nasal cavity induces the loss of OSNs (63-67), and anosmia induced by intranasal zinc has been suggested to occur in humans $(68,69)$. The immune response caused by exposure of the nasal cavity to toxic gases and metals is not well understood, but the regions of the OM affected by hydrogen sulfide inhalation is different from the regions affected by either intranasal Poly(I:C), LPS, or by mycotoxin inoculation. The OE can be subdivided into several zones based on the expression patterns of specific molecules (including olfactory receptors), and the dorsal medial meatus largely overlaps with zone 1 (aka dorsal zone) (70). Inhalation of hydrogen sulfide provoked necrotizing lesions of the OSNs predominantly localized in the zone $1(64,65)$, whereas the OE lining the dorsal medial meatus was not affected by the intranasal inoculation of Poly(I:C), SG, or RA solution $(7,11,14)$. The difference in susceptible portions in the OE may be attributed to the different flows of liquid and gas in the nasal cavity (71). Alternatively, molecules exclusively expressed by OSNs in zone 1 (e.g., NQO1, O-MACS, and Dvl-1) or in zone 2-4 (e.g., OCAM and Foxg1) may determine the susceptibility of OSNs to the environmental agents (72-76). Understanding the similarities and difference in immune responses to different environmental agents will help us to evaluate the risks to the CNS.

According to the olfactory vector hypothesis, some neurological disorders are caused or accelerated by agents entering the $\mathrm{OB}$ via the OM (17). Of interest, it was shown that either intranasally administered influenza virus, LPS, or MPTP (a synthetic neurotoxicant) caused selective decreases of dopamine neurons in the substantia nigra of mice $(21,27,77-79)$. The route from the OM to the substantia nigra, however, remains to be elucidated. The transport of viruses, bacteria, and metals from the nasal cavity to the OB has been reviewed by others (17, 20-22). Interestingly, Nipah virus propagates anterogradely in the hamster CNS via the olfactory pathway beginning in the $\mathrm{OB}(80)$. The agents entering the OB may spread further in the brain to cause neurological disorders. It is suggested that inflammatory responses can spread in the CNS both anterogradely or retrogradely via axonal projections (81). For instance, corneal inflammation induced by instillation of benzalkonium chloride damages primary sensory neurons in the trigeminal ganglion, leading to the activation of second-order neurons and glial cells in the brain stem and to the production of pro-inflammatory cytokines (82). Therefore, the inflammatory response may propagate in the brain from the primary olfactory tissue. Although this review focused on the effects on the OM, olfactory inflammation was also associated with atrophy of the OB; upregulation of the mRNA levels of inflammatory cytokines; infiltration of neutrophils; and/or activation of astrocytes and microglia $(7,8,11,43)$. These changes clearly should affect the $\mathrm{OB}$ neurons. Furthermore, intranasal LPS injection caused upregulation of TLR2 signals in the OB, which spread to other parts of the brain within $24 \mathrm{~h}$ (83). Further studies of neuroinflammation 
and damage in other brain regions will provide us with novel insights into the olfactory vector hypothesis and the pathogenesis of neurological disorders.

\section{CONCLUSION}

The olfactory system is a unique site where the peripheral nervous system and CNS are in close proximity. Since the OM is bathed in a sustained exposure of environmental agents that may cause inflammatory responses, the health of the CNS is likely to be heavily influenced by the immune status of the olfactory system. Big challenges in future are (1) to determine whether olfactory inflammation contribute to pathogenesis of neurodegenerative diseases; and (2) to determine whether olfactory inflammation

\section{REFERENCES}

1. Ahmad N, Zacharek MA. Allergic rhinitis and rhinosinusitis. Otolaryngol Clin North Am (2008) 41:267-281,v. doi:10.1016/j.otc.2007.11.010

2. Doty RL, Mishra A. Olfaction and its alteration by nasal obstruction, rhinitis, and rhinosinusitis. Laryngoscope (2001) 111:409-23. doi:10.1097/ 00005537-200103000-00008

3. Dalton P. Olfaction and anosmia in rhinosinusitis. Curr Allergy Asthma Rep (2004) 4:230-6. doi:10.1007/s11882-004-0031-3

4. Kern RC. Chronic sinusitis and anosmia: pathologic changes in the olfactory mucosa. Laryngoscope (2000) 110:1071-7. doi:10.1097/00005537200007000-00001

5. Wolfensberger M, Hummel T. Anti-inflammatory and surgical therapy of olfactory disorders related to sino-nasal disease. Chem Senses (2002) 27:617-22. doi:10.1093/chemse/27.7.617

6. Yee KK, Pribitkin EA, Cowart BJ, Rosen D, Feng P, Rawson NE. Analysis of the olfactory mucosa in chronic rhinosinusitis. Ann N Y Acad Sci (2009) 1170:590-5. doi:10.1111/j.1749-6632.2009.04364.x

7. Islam Z, Harkema JR, Pestka JJ. Satratoxin G from the black mold Stachybotrys chartarum evokes olfactory sensory neuron loss and inflammation in the murine nose and brain. Environ Health Perspect (2006) 114:1099-107. doi:10.1289/ehp. 8854

8. Islam Z, Amuzie CJ, Harkema JR, Pestka JJ. Neurotoxicity and inflammation in the nasal airways of mice exposed to the macrocyclic trichothecene mycotoxin roridin a: kinetics and potentiation by bacterial lipopolysaccharide coexposure. Toxicol Sci (2007) 98:526-41. doi:10.1093/ toxsci/kfm 102

9. Yagi S, Tsukatani T, Yata T, Tsukioka F, Miwa T, Furukawa M. Lipopolysaccharide-induced apoptosis of olfactory receptor neurons in rats. Acta Otolaryngol (2007) 127:748-53. doi:10.1080/00016480601002062

10. Epstein VA, Bryce PJ, Conley DB, Kern RC, Robinson AM. Intranasal Aspergillus fumigatus exposure induces eosinophilic inflammation and olfactory sensory neuron cell death in mice. Otolaryngol Head Neck Surg (2008) 138:334-9. doi:10.1016/j.otohns.2007.11.029

11. Corps KN, Islam Z, Pestka JJ, Harkema JR. Neurotoxic, inflammatory, and mucosecretory responses in the nasal airways of mice repeatedly exposed to the macrocyclic trichothecene mycotoxin roridin A: dose-response and persistence of injury. Toxicol Pathol (2010) 38:429-51. doi:10.1177/ 0192623310364026

12. Lane AP, Turner J, May L, Reed R. A genetic model of chronic rhinosinusitis-associated olfactory inflammation reveals reversible functional impairment and dramatic neuroepithelial reorganization. J Neurosci (2010) 30:2324-9. doi:10.1523/JNEUROSCI.4507-09.2010

13. Carey SA, Plopper CG, Hyde DM, Islam Z, Pestka JJ, Harkema JR. Satratoxin-G from the black mold Stachybotrys chartarum induces rhinitis and apoptosis of olfactory sensory neurons in the nasal airways of rhesus monkeys. Toxicol Pathol (2012) 40:887-98. doi:10.1177/ 0192623312444028

14. Kanaya K, Kondo K, Suzukawa K, Sakamoto T, Kikuta S, Okada K, et al. Innate immune responses and neuroepithelial degeneration and sequentially affect the immune status of the CNS via the olfactory pathways in the brain.

\section{AUTHOR CONTRIBUTIONS}

FI and SH-I searched and reviewed previous works and wrote this article.

\section{ACKNOWLEDGMENTS}

The authors thank Drs. Kent Vrana, Richard Mailman, and Robert Levenson for critical reading of this manuscript. The authors apologize to those whose work was not included here due to space limitations.

regeneration in the mouse olfactory mucosa induced by intranasal administration of Poly(I:C). Cell Tissue Res (2014) 357:279-99. doi:10.1007/s00441014-1848-2

15. de Lau LM, Breteler MM. Epidemiology of Parkinson's disease. Lancet Neurol (2006) 5:525-35. doi:10.1016/S1474-4422(06)70471-9

16. Yegambaram M, Manivannan B, Beach TG, Halden RU. Role of environmental contaminants in the etiology of Alzheimer's disease: a review. Curr Alzheimer Res (2015) 12:116-46. doi:10.2174/1567205012666150 204121719

17. Doty RL. The olfactory vector hypothesis of neurodegenerative disease: is it viable? Ann Neurol (2008) 63:7-15. doi:10.1002/ana.21327

18. Wesson DW, Wilson DA, Nixon RA. Should olfactory dysfunction be used as a biomarker of Alzheimer's disease? Expert Rev Neurother (2010) 10:633-5. doi:10.1586/ern.10.33

19. Doty RL. Olfactory dysfunction in Parkinson disease. Nat Rev Neurol (2012) 8:329-39. doi:10.1038/nrneurol.2012.80

20. Sunderman FW Jr. Nasal toxicity, carcinogenicity, and olfactory uptake of metals. Ann Clin Lab Sci (2001) 31:3-24.

21. Prediger RD, Aguiar AS Jr, Matheus FC, Walz R, Antoury L, RaismanVozari R, et al. Intranasal administration of neurotoxicants in animals: support for the olfactory vector hypothesis of Parkinson's disease. Neurotox Res (2012) 21:90-116. doi:10.1007/s12640-011-9281-8

22. van Riel D, Verdijk R, Kuiken T. The olfactory nerve: a shortcut for influenza and other viral diseases into the central nervous system. J Pathol (2015) 235:277-87. doi:10.1002/path.4461

23. McGeer PL, Itagaki S, Tago H, Mcgeer EG. Reactive microglia in patients with senile dementia of the Alzheimer type are positive for the histocompatibility glycoprotein HLA-DR. Neurosci Lett (1987) 79:195-200. doi:10.1016/0304-3940(87)90696-3

24. McGeer PL, Itagaki S, Mcgeer EG. Expression of the histocompatibility glycoprotein HLA-DR in neurological disease. Acta Neuropathol (1988) 76:550-7. doi:10.1007/BF00689592

25. Knott C, Wilkin GP, Stern G. Astrocytes and microglia in the substantia nigra and caudate-putamen in Parkinson's disease. Parkinsonism Relat Disord (1999) 5:115-22. doi:10.1016/S1353-8020(99)00022-X

26. Doorn KJ, Goudriaan A, Blits-Huizinga C, Bol JG, Rozemuller AJ, Hoogland $\mathrm{PV}$, et al. Increased amoeboid microglial density in the olfactory bulb of Parkinson's and Alzheimer's patients. Brain Pathol (2014) 24:152-65. doi:10.1111/bpa.12088

27. He Q, Yu W, Wu J, Chen C, Lou Z, Zhang Q, et al. Intranasal LPS-mediated Parkinson's model challenges the pathogenesis of nasal cavity and environmental toxins. PLoS One (2013) 8:e78418. doi:10.1371/journal.pone. 0078418

28. Lema Tome CM, Tyson T, Rey NL, Grathwohl S, Britschgi M, Brundin P. Inflammation and alpha-synuclein's prion-like behavior in Parkinson's disease - is there a link? Mol Neurobiol (2013) 47:561-74. doi:10.1007/s12035012-8267-8

29. Bower JH, Maraganore DM, Peterson BJ, Ahlskog JE, Rocca WA. Immunologic diseases, anti-inflammatory drugs, and Parkinson disease: a case-control study. Neurology (2006) 67:494-6. doi:10.1212/01.wnl.0000227906.99570.cc 
30. Graziadei GA, Graziadei PP. Neurogenesis and neuron regeneration in the olfactory system of mammals. II. Degeneration and reconstitution of the olfactory sensory neurons after axotomy. J Neurocytol (1979) 8:197-213. doi:10.1007/BF01175561

31. Brann JH, Firestein SJ. A lifetime of neurogenesis in the olfactory system. Front Neurosci (2014) 8:182. doi:10.3389/fnins.2014.00182

32. Desrosiers M. Refractory chronic rhinosinusitis: pathophysiology and management of chronic rhinosinusitis persisting after endoscopic sinus surgery. Curr Allergy Asthma Rep (2004) 4:200-7. doi:10.1007/s11882-0040027-z

33. Jacob A, Faddis BT, Chole RA. Chronic bacterial rhinosinusitis: description of a mouse model. Arch Otolaryngol Head Neck Surg (2001) 127:657-64. doi:10.1001/archotol.127.6.657

34. Lindsay R, Slaughter T, Britton-Webb J, Mog SR, Conran R, Tadros M, et al. Development of a murine model of chronic rhinosinusitis. Otolaryngol Head Neck Surg (2006) 134:724-730; discussion 731-722. doi:10.1016/j. otohns.2005.11.048

35. Matsumoto M, Seya T. TLR3: interferon induction by double-stranded RNA including poly(I:C). Adv Drug Deliv Rev (2008) 60:805-12. doi:10.1016/j. addr.2007.11.005

36. Miller SI, Ernst RK, Bader MW. LPS, TLR4 and infectious disease diversity. Nat Rev Microbiol (2005) 3:36-46. doi:10.1038/nrmicro1068

37. Block ML, Calderon-Garciduenas L. Air pollution: mechanisms of neuroinflammation and CNS disease. Trends Neurosci (2009) 32:506-16. doi:10.1016/j. tins.2009.05.009

38. Hasegawa-Ishii S, Inaba M, Umegaki H, Unno K, Wakabayashi K, Shimada A. Endotoxemia-induced cytokine-mediated responses of hippocampal astrocytes transmitted by cells of the brain-immune interface. Sci Rep (2016) 6:25457. doi:10.1038/srep25457

39. Islam Z, Shinozuka J, Harkema JR, Pestka JJ. Purification and comparative neurotoxicity of the trichothecenes satratoxin $G$ and roridin L2 from Stachybotrys chartarum. J Toxicol Environ Health A (2009) 72:1242-51. doi:10.1080/15287390903129234

40. Vincent AJ, Choi-Lundberg DL, Harris JA, West AK, Chuah MI. Bacteria and PAMPs activate nuclear factor kappaB and Gro production in a subset of olfactory ensheathing cells and astrocytes but not in Schwann cells. Glia (2007) 55:905-16. doi:10.1002/glia.20512

41. Pham CT. Neutrophil serine proteases: specific regulators of inflammation. Nat Rev Immunol (2006) 6:541-50. doi:10.1038/nri1841

42. Sultan B, May LA, Lane AP. The role of TNF-alpha in inflammatory olfactory loss. Laryngoscope (2011) 121:2481-6. doi:10.1002/lary.22190

43. Herbert RP, Harris J, Chong KP, Chapman J, West AK, Chuah MI. Cytokines and olfactory bulb microglia in response to bacterial challenge in the compromised primary olfactory pathway. J Neuroinflammation (2012) 9:109. doi:10.1186/1742-2094-9-109

44. Schwob JE. Neural regeneration and the peripheral olfactory system. Anat Rec (2002) 269:33-49. doi:10.1002/ar.10047

45. Duggan CD, Ngai J. Scent of a stem cell. Nat Neurosci (2007) 10:673-4. doi:10.1038/nn0607-673

46. Jang W, Youngentob SL, Schwob JE. Globose basal cells are required for reconstitution of olfactory epithelium after methyl bromide lesion. J Comp Neurol (2003) 460:123-40. doi:10.1002/cne.10642

47. Ruitenberg MJ, Vukovic J, Blomster L, Hall JM, Jung S, Filgueira L, et al. CX3CL1/fractalkine regulates branching and migration of monocyte-derived cells in the mouse olfactory epithelium. J Neuroimmunol (2008) 205:80-5. doi:10.1016/j.jneuroim.2008.09.010

48. Su Z, Chen J, Qiu Y, Yuan Y, Zhu F, Zhu Y, et al. Olfactory ensheathing cells: the primary innate immunocytes in the olfactory pathway to engulf apoptotic olfactory nerve debris. Glia (2013) 61:490-503. doi:10.1002/glia.22450

49. Nazareth L, Lineburg KE, Chuah MI, Tello Velasquez J, Chehrehasa F, St John $\mathrm{JA}$, et al. Olfactory ensheathing cells are the main phagocytic cells that remove axon debris during early development of the olfactory system. J Comp Neurol (2015) 523:479-94. doi:10.1002/cne.23694

50. Costanzo RM, Graziadei PP. A quantitative analysis of changes in the olfactory epithelium following bulbectomy in hamster. J Comp Neurol (1983) 215:370-81. doi:10.1002/cne.902150403

51. Schwartz Levey M, Chikaraishi DM, Kauer JS. Characterization of potential precursor populations in the mouse olfactory epithelium using immunocytochemistry and autoradiography. J Neurosci (1991) 11:3556-64.
52. Nan B, Getchell ML, Partin JV, Getchell TV. Leukemia inhibitory factor, interleukin-6, and their receptors are expressed transiently in the olfactory mucosa after target ablation. J Comp Neurol (2001) 435:60-77. doi:10.1002/ cne.1193

53. Heron PM, Stromberg AJ, Breheny P, Mcclintock TS. Molecular events in the cell types of the olfactory epithelium during adult neurogenesis. Mol Brain (2013) 6:49. doi:10.1186/1756-6606-6-49

54. Chehrehasa F, Ekberg JA, Lineburg K, Amaya D, Mackay-Sim A, St John JA. Two phases of replacement replenish the olfactory ensheathing cell population after injury in postnatal mice. Glia (2012) 60:322-32. doi:10.1002/ glia.22267

55. Suzuki Y, Schafer J, Farbman AI. Phagocytic cells in the rat olfactory epithelium after bulbectomy. Exp Neurol (1995) 136:225-33. doi:10.1006/exnr. 1995.1099

56. Getchell TV, Shah DS, Partin JV, Subhedar NK, Getchell ML. Leukemia inhibitory factor mRNA expression is upregulated in macrophages and olfactory receptor neurons after target ablation. J Neurosci Res (2002) 67:246-54. doi:10.1002/jnr.10090

57. Getchell TV, Subhedar NK, Shah DS, Hackley G, Partin JV, Sen G, et al. Chemokine regulation of macrophage recruitment into the olfactory epithelium following target ablation: involvement of macrophage inflammatory protein-1alpha and monocyte chemoattractant protein-1. JNeurosci Res (2002) 70:784-93. doi:10.1002/jnr.10432

58. Bauer S, Rasika S, Han J, Mauduit C, Raccurt M, Morel G, et al. Leukemia inhibitory factor is a key signal for injury-induced neurogenesis in the adult mouse olfactory epithelium. J Neurosci (2003) 23:1792-803.

59. Lopez-Arenas E, Mackay-Sim A, Bacigalupo J, Sulz L. Leukaemia inhibitory factor stimulates proliferation of olfactory neuronal progenitors via inducible nitric oxide synthase. PLoS One (2012) 7:e45018. doi:10.1371/journal. pone. 0045018

60. Harris JA, West AK, Chuah MI. Olfactory ensheathing cells: nitric oxide production and innate immunity. Glia (2009) 57:1848-57. doi:10.1002/ glia.20899

61. Pozharskaya T, Liang J, Lane AP. Regulation of inflammation-associated olfactory neuronal death and regeneration by the type II tumor necrosis factor receptor. Int Forum Allergy Rhinol (2013) 3:740-7. doi:10.1002/ alr.21187

62. Xie F, Fang C, Schnittke N, Schwob JE, Ding X. Mechanisms of permanent loss of olfactory receptor neurons induced by the herbicide 2,6-dichlorobenzonitrile: effects on stem cells and noninvolvement of acute induction of the inflammatory cytokine IL-6. Toxicol Appl Pharmacol (2013) 272:598-607. doi:10.1016/j.taap.2013.07.020

63. Lopez A, Prior M, Yong S, Lillie L, Lefebvre M. Nasal lesions in rats exposed to hydrogen sulfide for four hours. Am J Vet Res (1988) 49:1107-11.

64. Brenneman KA, James RA, Gross EA, Dorman DC. Olfactory neuron loss in adult male $\mathrm{CD}$ rats following subchronic inhalation exposure to hydrogen sulfide. Toxicol Pathol (2000) 28:326-33. doi:10.1177/ 019262330002800213

65. Brenneman KA, Meleason DF, Sar M, Marshall MW, James RA, Gross $\mathrm{EA}$, et al. Olfactory mucosal necrosis in male $\mathrm{CD}$ rats following acute inhalation exposure to hydrogen sulfide: reversibility and the possible role of regional metabolism. Toxicol Pathol (2002) 30:200-8. doi:10.1080/ 019262302753559533

66. Dorman DC, Moulin FJ, Mcmanus BE, Mahle KC, James RA, Struve MF. Cytochrome oxidase inhibition induced by acute hydrogen sulfide inhalation: correlation with tissue sulfide concentrations in the rat brain, liver, lung, and nasal epithelium. Toxicol Sci (2002) 65:18-25. doi:10.1093/ toxsci/65.1.18

67. McBride K, Slotnick B, Margolis FL. Does intranasal application of zinc sulfate produce anosmia in the mouse? An olfactometric and anatomical study. Chem Senses (2003) 28:659-70. doi:10.1093/chemse/bjg053

68. Tisdall FF, Brown A, Defries RD. Persistent anosmia following zinc sulfate nasal spraying. J Pediatr (1938) 13:60-2. doi:10.1016/S0022-3476(38)80128-1

69. Alexander TH, Davidson TM. Intranasal zinc and anosmia: the zinc-induced anosmia syndrome. Laryngoscope (2006) 116:217-20. doi:10.1097/01. mlg.0000191549.17796.13

70. Ressler KJ, Sullivan SL, Buck LB. A zonal organization of odorant receptor gene expression in the olfactory epithelium. Cell (1993) 73:597-609. doi:10.1016/0092-8674(93)90145-G 
71. Schroeter JD, Kimbell JS, Andersen ME, Dorman DC. Use of a pharmacokinetic-driven computational fluid dynamics model to predict nasal extraction of hydrogen sulfide in rats and humans. Toxicol Sci (2006) 94:359-67. doi:10.1093/toxsci/kfl112

72. Yoshihara Y, Kawasaki M, Tamada A, Fujita H, Hayashi H, Kagamiyama $\mathrm{H}$, et al. OCAM: a new member of the neural cell adhesion molecule family related to zone-to-zone projection of olfactory and vomeronasal axons. J Neurosci (1997) 17:5830-42.

73. Oka Y, Kobayakawa K, Nishizumi H, Miyamichi K, Hirose S, Tsuboi A, et al. O-MACS, a novel member of the medium-chain acyl-CoA synthetase family, specifically expressed in the olfactory epithelium in a zone-specific manner. Eur J Biochem (2003) 270:1995-2004. doi:10.1046/j.1432-1033.2003. 03571.x

74. Gussing F, Bohm S. NQO1 activity in the main and the accessory olfactory systems correlates with the zonal topography of projection maps. Eur J Neurosci (2004) 19:2511-8. doi:10.1111/j.0953-816X.2004.03331.x

75. Duggan CD, Demaria S, Baudhuin A, Stafford D, Ngai J. Foxg1 is required for development of the vertebrate olfactory system. J Neurosci (2008) 28:5229-39. doi:10.1523/JNEUROSCI.1134-08.2008

76. Rodriguez-Gil DJ, Hu W, Greer CA. Dishevelled proteins are associated with olfactory sensory neuron presynaptic terminals. PLoS One (2013) 8:e56561. doi:10.1371/journal.pone.0056561

77. Rojo AI, Montero C, Salazar M, Close RM, Fernandez-Ruiz J, SanchezGonzalez MA, et al. Persistent penetration of MPTP through the nasal route induces Parkinson's disease in mice. Eur J Neurosci (2006) 24:1874-84. doi:10.1111/j.1460-9568.2006.05060.x

78. Jang H, Boltz D, Sturm-Ramirez K, Shepherd KR, Jiao Y, Webster R, et al. Highly pathogenic H5N1 influenza virus can enter the central nervous system and induce neuroinflammation and neurodegeneration. Proc Natl Acad Sci U S A (2009) 106:14063-8. doi:10.1073/pnas.0900096106
79. Tristao FS, Amar M, Latrous I, Del-Bel EA, Prediger RD, Raisman-Vozari R. Evaluation of nigrostriatal neurodegeneration and neuroinflammation following repeated intranasal 1-methyl-4-phenyl-1,2,3,6-tetrahydropyridine (MPTP) administration in mice, an experimental model of Parkinson's disease. Neurotox Res (2014) 25:24-32. doi:10.1007/s12640-013-9401-8

80. Munster VJ, Prescott JB, Bushmaker T, Long D, Rosenke R, Thomas T, et al. Rapid Nipah virus entry into the central nervous system of hamsters via the olfactory route. Sci Rep (2012) 2:736. doi:10.1038/srep00736

81. Cooper MS, Clark VP. Neuroinflammation, neuroautoimmunity, and the co-morbidities of complex regional pain syndrome. JNeuroimmune Pharmacol (2013) 8:452-69. doi:10.1007/s11481-012-9392-x

82. Launay PS, Reboussin E, Liang H, Kessal K, Godefroy D, Rostene W, et al. Ocular inflammation induces trigeminal pain, peripheral and central neuroinflammatory mechanisms. Neurobiol Dis (2016) 88:16-28. doi:10.1016/j. nbd.2015.12.017

83. Lalancette-Hebert M, Phaneuf D, Soucy G, Weng YC, Kriz J. Live imaging of Toll-like receptor 2 response in cerebral ischaemia reveals a role of olfactory bulb microglia as modulators of inflammation. Brain (2009) 132:940-54. doi:10.1093/brain/awn345

Conflict of Interest Statement: The authors declare that the research was conducted in the absence of any commercial or financial relationships that could be construed as a potential conflict of interest.

Copyright (c) 2016 Imamura and Hasegawa-Ishii. This is an open-access article distributed under the terms of the Creative Commons Attribution License (CC BY). The use, distribution or reproduction in other forums is permitted, provided the original author(s) or licensor are credited and that the original publication in this journal is cited, in accordance with accepted academic practice. No use, distribution or reproduction is permitted which does not comply with these terms. 